\title{
viewpoint
}

\section{Publish and perish}

\author{
Hedging and fraud in scientific discourse
}

\author{
Marie-Claude Roland
}

$\mathrm{T}$ he nature of publicly funded research is changing. Both developed and developing nations are increasing their investments in scientific research, either to maintain their technological lead or to catch up with advanced societies. The focus on research as a basis for a 'knowledge society' has raised public awareness of science and its impact on society, with repercussions for science and its public image. Demands for accountability, transparency and quality - and a greater focus on fraud, misconduct and plagiarism-are growing concerns both in the research community and in society. To secure and maintain public support for research, scientists must increasingly show ethical and responsible conduct in their research, and improve their oral and written communication skills to transmit and discuss relevant knowledge, its possible social implications and the excitement of doing research.

\section{Demands for accountability, transparency and quality_-and a greater focus on fraud, misconduct and plagiarism - are growing concerns both in the research community and in society}

This changing paradigm of scientific research and communication-from a deficit model to a democratic process that involves all stakeholders-suggests that scientists must realize the old truth that science is communication: "Science exists because scientists are writers and speakers. [...] As a form of knowledge, scientific understanding is inseparable from the written and spoken word. There are no boundaries, no walls between the doing of science

\section{I argue that the communication and writing practices of researchers_-ranging from scientific papers to conference presentations, posters and internal institutional documents-present a threat to the scientific enterprise}

and the communication of it; communicating is the doing of science" (Montgomery, 2003). However, scientists' communication practices - with each other and with a non-specialist audience-leave much room for improvement. The average scientific publication is almost impossible to understand for a non-specialist, even a fellow scientist. Furthermore, a lack of clarity, commitment and conciseness in scientific communication paves the way for scientific misconduct, such as fraud and plagiarism.

In the light of what seems to be a series of fraudulent high-profile publications, social scientists have begun to take a closer look at the practices and structures within scientific research that might encourage, or at least enable, such misconduct. With some justification, they asked: "Why does the scientific community ascribe misconduct to individual behaviour rather than acknowledging that it is the tip of the iceberg of normal behaviour?" (Franzen et al, 2007). Here, I argue that the communication and writing practices of researchers-ranging from scientific papers to conference presentations, posters and internal institutional documents-present a threat to the scientific enterprise. In fact, communication and the use - or rather abuse_-of language are, in my opinion, an important factor in institutional misconduct. However, the scientific community itself does not regard it as a major problem —as Franzen and colleagues commented, "The community's tendency to restrict fraud to individuals therefore acts to defend the social and communication system of science."

realized that the scientific juggernaut was on course to hit this iceberg after analysing scientific writing in its various forms-articles, presentations, posters, research proposals, institutional literature and so forth-and observing writing practices by working closely with researchers (Roland, 1995). This article presents the preliminary results of analysing scientific articles and referee reports - 500 in total-and comparing them with the norms and standards that codify scientific writing (ANSI, 1979a,b; AFNOR, 1984). I also interviewed researchers and referees, and analysed their discourse to ascertain their attitude towards writing: what it means to them, how important it is, and whether and how they were prepared for the task. In addition, I asked them about the role of a supervisor-for example, how they transmit their knowledge about writing standards and experiences, and the time they devote to working with students on their papers.

Over 15 years, I have taught approximately 1,600 junior and senior researchers from a broad range of disciplines-life sciences, mathematics, physics and social sciences, for example-and from various institutions in Europe and Canada in Réflexives ${ }^{\circledR}$ training seminars. These seminars are designed to help get results published as quickly and efficiently as possible. However, when I realized that the researchers' problems were less with writing itself and more with designing research strategy and placing results in context, I adapted the seminars accordingly. With the 
cooperation of researchers who acknowledged their weaknesses, we tackled the real issues behind the difficulties of writing: what are the research questions underlying the experiments? How did you develop your specific research question? What are the scientific and societal issues of your research? What impact will it have? What is your research strategy?

My aim here is to show that scientific communication-oral and written-has degenerated into a style that acts to conceal the authors' ideas, intentions and character. In particular, hedging-when a writer withholds full commitment to his statements-and its avatars plagiarism and misquotation, have spread to such an extent that they create ambiguity, and in many cases illegibility and misinterpretations, which could be regarded as a form of fraud, defined by the Merriam-Webster Dictionary as "an act of deceiving or misrepresenting". I will further outline the consequences that this attitude has on young researchers and on the ability to sustain publicly funded research.

I n general, scientific discourse has evolved into a 'ready-to-write' model, which has progressively provided researchers with an ersatz 'ready-to-think' model. As a consequence of this lackadaisical attitude, hedging in its various forms has spread so widely in scientific discourse that it has become a main source of what Franzen and colleagues call institutional fraud. This already has negative consequences for the training of young researchers and might cause them additional difficulties when assuming their role in society. Here, I focus on four distinctive features of hedging: impersonal style, passive voice, modal verbs and the descriptive approach. All are found in the two most important sections of any scientific paper or communication: the introduction, which should present the research objectives in the larger context; and the discussion, in which the implications and future directions of the work are debated.

Scientific writing contradicts the norms and standards of the scientific community on which most journals' recommendations to authors are based. Journals' guidelines for referees and for authors, and national and international standards, reproduce and conform to the conclusions of the Vancouver Group-now the International Committee of Medical Journal Editors-on the content, structure and style of papers for publication (ICMJE, 2006). The same norms apply to oral presentations, abstracts, papers and posters (see sidebar).

However, an increasing number of papers violate these rules. Many papers lack clear rationales and scientific objectives, and their discussions often ramble. This is not just the view of a linguist-by analysing referees' reports, I found that they often point to the discussion and introduction as being the weakest parts of a paper because they lack focus and a clearly formulated research question, and use weak comparisons. The following comments, from among hundreds of similar referee reports, highlight the extent of this problem: "The introduction does not really suggest why the authors did what they did, beyond the vague statement that 'we investigated the effect of $x x^{\prime}$. If they had any specific objective to their study, it is not stated"; "Please establish the clear rationale for your study in the introduction in relation to your hypotheses"; "The weakest part of this text is probably the Discussion. The results invoke questions that are left unformulated and ignored. The focus of the discussion on certain theoretical considerations leaves one with the impression 'so what'."

\section{In general, scientific discourse has evolved into a 'ready-to-write' model, which has progressively provided researchers with an ersatz'ready-to-think' model}

In addition, many researchers adopt a descriptive rather than an informative or argumentative approach when communicating their work. The following quote from a referee is about the introduction and discussion sections of a paper in which references were presented more like a catalogue than a well-constructed body of arguments: "I am not convinced that the level of analysis given here is worth publishing in this journal $[\ldots]$ and I would prefer the authors to resubmit, including analyses that really address the issues of causes and effect in xxx."

Although author guidelines and other recommendations state that the personal and active voice is preferred for clarity and conciseness, most papers and even oral communications pervasively use the impersonal style and passive voice. Suddenly, the animals used in the experiments were

\section{GENERAL RULES \\ AND RECOMMENDATIONS FOR SCIENTIFIC WRITING}

Extracts from American National Standard for the Preparation of Scientific Papers for Written or Oral Presentation (ANSI, 1979b):

The introduction should make clear the aim of the paper; the authors' purpose in undertaking the work described, including any hypothesis to be tested; and the relationship of the work to a larger field of inquiry. Authors may think that the purpose of the work will be obvious to experts in the field, but they should, nevertheless, make it explicit (or at least evident) and intelligible to those who are not specialists. Readers should learn from the introduction exactly what question(s) the authors are to address.

In the discussion, the authors usually relate their experiments, calculations, or proofs to one another and to previous and related findings, and discuss the significance and limitations of their conclusions. They should clearly demarcate their work from the work of others and be scrupulous in including contradictory evidence. To aid the reader, the authors should discuss all results and interpretations in the context of an explicitly enunciated hypothesis that is being advanced or examined.

Good scientific writing is logical, clear, precise, direct, and concise. Its main scientific quality lies in precision, and all words should therefore be used in an exact sense. If the sense intended is different from that commonly understood or defined in dictionaries, the usage should be carefully explained. [...] The language used should be as simple as is compatible with the subject and as concise as is compatible with ready understanding. An extremely terse style, which can be cryptic, is as much a barrier to communication as is verbosity.

Authors should minimize the use of verbs in the third person, passive voice. When a verb concerns the interaction of inanimate objects ("the membrane is acted upon by the drug"), the active voice is usually preferable ("the drug acts on the membrane") because it is more direct and concise. When a verb concerns an author's belief or conjecture, use of the interpersonal passive ("it is thought" or "it is suggested") is highly inappropriate. When a verb concerns action by the author, the first person should be used, especially in matters of experimental design ("to eliminate this possibility, I did the following experiment"). Constant use of the first person is not advisable, however, since it may distract the reader from the subject of the paper. 
conducting the research, analysing the results and speculating about the meaning-all because a real subject is missing. An example of such a typical 'dangling' construction is: "After analysing the results, the mice were injected with a solution." In addition, the use of 'may' and 'might' is widespread and combines with the impersonal and passive voice to create a highly unreadable style that avoids taking any personal responsibility or stance.

$\mathrm{T}$ he question then is why scientists take so little care in communicating their work when they have invested so much into gathering their results. Working with junior and senior researchers and with student-supervisor pairs, my colleagues and I found that identifying one's research objectives, and clarifying one's work interest and impact was often a long and tedious process (Roland et al, 2002). When we further studied the relationship between students and their supervisors, and specifically how a supervisor's research subject becomes a PhD student's research project, we identified two common situations: the student is given a precise list of tasks to complete, with the supervisor retaining control over the scientific background; or the student is given a subject and left to tackle it alone. Either way, the results are the same: students rarely have an opportunity to take intellectual ownership of a scientific problem or questions, and have little incentive to participate in a larger controversy or to formulate their own specific research subjects.

Writing practices thrive on mimetic behaviour: students learn from their supervisors and from the papers they read, and often they learn to import-copy and paste-elements of published papers, a strategy that I call the 'ready-to-write' model. This model has evolved into a form of writing from which the researcher is intentionally absent-by the heavy use of passive and impersonal forms-and is encouraged and advocated by supervisors and journal editors. Supervisors are often not interested or do not have the time to explain or analyse the subtleties of language in scientific writing, or might be unable to do so-especially if their native language is not English. Acquiring good communication skills is still considered an 'add on' in students' training, and is not seen as important for the responsible conduct of research, or as an intrinsic component of a researcher's profession.
$\mathrm{H}$ edging is a distinctive feature of what can be called tribal communication among researchers. According to Hyland (1998), hedges are not negative indicators of imprecision and fuzziness, but are essential means by which reader and writer negotiate the acceptance of claims. Writers seek to gain acceptance of the most significant claims possible, while acknowledging the place of their work in the research literature: claims must be both new and related to the discipline to be worth publishing. This tension is an essential dimension in scientific discourse.

Hyland therefore distinguishes two main types of hedges, which both have rhetorical and epistemic purposes. First are "content-oriented" or "accuracy-oriented" hedges, the function of which is "to increase the exactness with which a proposition is expressed", and "writer-oriented hedges", which authors use to avoid commitment. Such hedges have a double purpose: "on the one hand the writer seeks to present statements with appropriate accuracy, on the other to make the strongest claim possible while limiting the damage of being wrong." Second are "readeroriented hedges" that address the social interactions between writer and reader. Writers tend to protect their reputation; for example, criticism is often diffuse and does not attribute what is criticized to any particular source- "In our study, the existence of $x x x$ isoforms questions the validity of earlier results...." Therefore, hedges enable writers to manage disagreement without creating open conflict.

However, as Hyland remarks, hedging must be considered in its social, psychological, historical and political context. Under pressure to publish papers at a steady rhythm - 'publish or perish!'researchers have succumbed to the 'readyto-write' model and 'fill in the blanks'. This has led to an impersonal, coded newspeak that leaves the author's character undetectable and the ideas disguised, as Lawrence \& Locke (1997) remarked. Robert Day, famous for his handbook on scientific writing, which has become a reference in university libraries, warned that "...in short many good scientists are poor writers.... Some scientists became good writers nonetheless. Many, however, learned only how to repeat all that is incorrect with respect to the prose and style of authors before them, thus establishing a system of error in perpetuity" (Day, 1989). The French writer Georges Pérec was so sensitive to the use of language that he swiftly picked up on the overuse of hedging in scientific papers and wrote his famous pastiche known as 'Cantatrix Sopranica' (Pérec, 1980).

In addition to producing dull papers, which are read only by the small group who have a vested interest in the subject matter, such practices actually pave the way for fraud. This is part of "the institutionally induced deviant behaviour of many scientists" (Franzen et al, 2007). By using the 'ready-to-write' model and relying on hedging, researchers take less responsibility for what they write while often plagiarizing or misquoting published papers. Sentences abound with words or phrases such as 'putative', 'may', 'possibly', 'is known to', or 'is thought to be', or expressions such as 'play a key/central/ crucial role in', which mask reality or fail to formulate research questions or hypotheses. Instead of clearly delineating the meaning of what they want to convey, authors accumulate hedges, opening the door to misinterpretation. The US Office for Research Integrity and other similar institutions warn against such practices and organize courses in the responsible conduct of research.

\section{Writing practices thrive on mimetic behaviour: students learn from their supervisors and from the papers they read, and often they learn to import-copy and paste- elements of published papers, a strategy that I call the 'ready-to- write' model}

Finally, hedging has deprived researchers of a taste for argumentation, debate and controversy: the 'ready-to-write' model has entailed a 'ready-to-think' attitude. As one journal editor wrote to an author: "The paper is written in the most verbose, repetitious, expanded style I have ever seen. (...) This is [a] fundamental problem with this kind of writing. It is not really a question of writing style or even of good English: it is a question of clear thinking or perhaps just of thinking at all." If we consider that communication is the doing of science, such practices have disastrous consequences for the quality of science. 


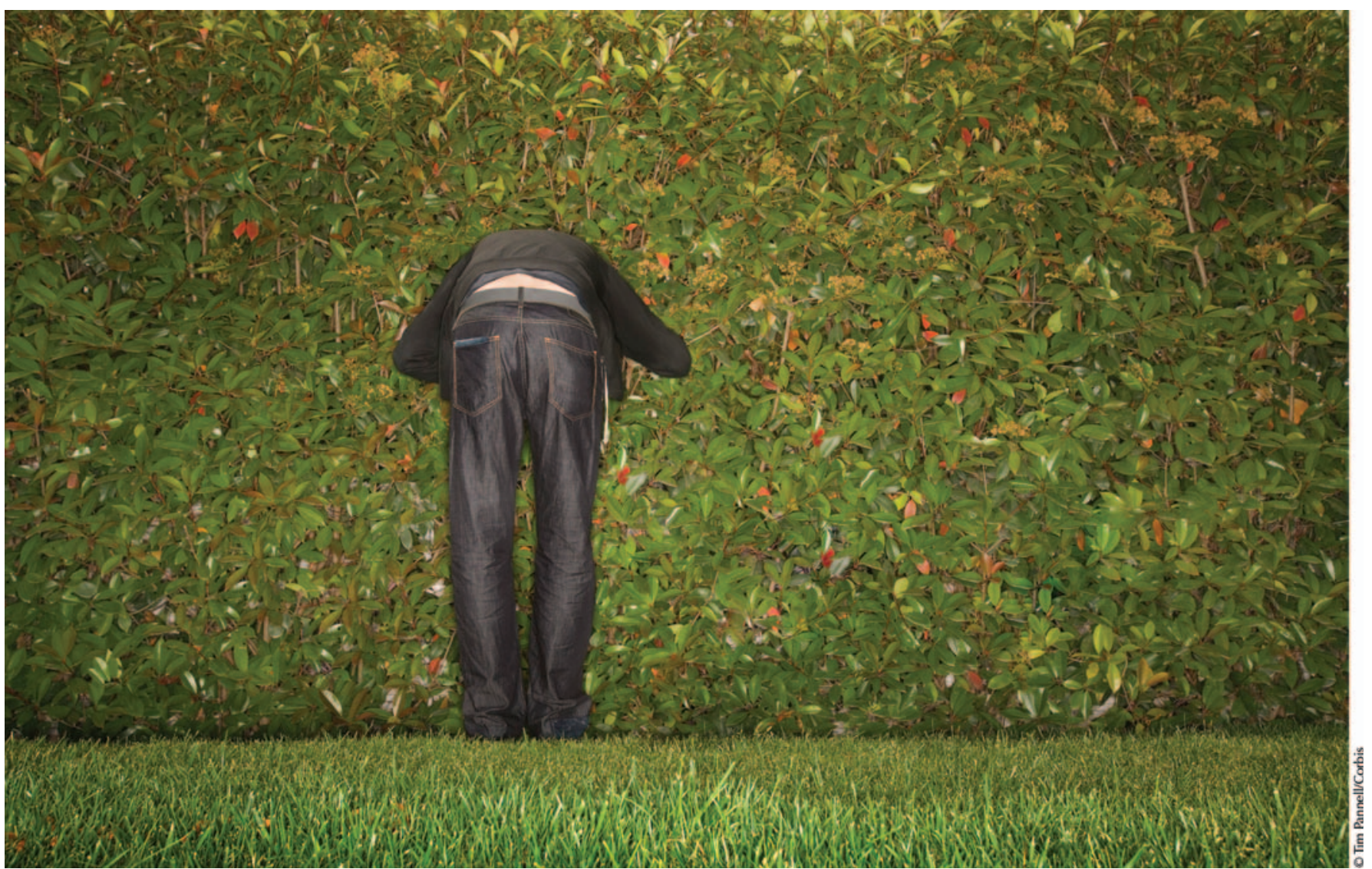

A a linguist, I am naturally sensitive to the use of the word 'quality' when it is discussed with regard to science; therefore, its usage and terminology deserve a few introductory remarks. Quality has always been expected from researchers, and it must cover all three stages in the research process: definition of the research objectives in terms of opportunity and feasibility; traceability of actions and materials at the experimental stage; and communication of relevant, reliable and original results (ESF, 2000; AFNOR, 2001). However, my colleagues and I have observed that researchers accept and emphasize quality at the second stage-process, material and methodsbut are reluctant to address it at stages one and three. It is worrying when we talk about excellence and even elite research, but fail to apply the same quality standards to all stages of the research process.

Heavy use of hedging in its various forms prevents researchers from committing themselves to their research subject and from taking risks. This, I argue, is a major reason for common difficulties in writing: for example, researchers are reluctant to use the modal verb 'will', which shows commitment to action, preferring instead to use 'may' or 'might'. I further propose that hedging is bound to hamper the role of scientists in society. Difficulties in formulating one's objectives and relating one's work with a well-prepared hypothesis create communication barriers between researchers and funding bodies or politicians (Gascoigne, 2001; EFB, 2004). By reducing their exposure to various risks, hedging their confidence in the accuracy of knowledge and insuring themselves against any negative effects - what Hyland (1998) calls "defensive lack of commitment"—researchers leave the interpretation to journalists, politicians or any other interested party and therefore create the conditions for manipulation and misinterpretation. As for funding bodies, they, in turn, are reluctant to grant money to people who shun risks. In general, the risk-avoiding behaviour of scientists is bound to erode further society's trust in scientific results and integrity.

To conclude, I argue that the way young generations are trained in the art of communication "threatens the foundations of science as an institution" (Franzen et al, 2007). "Just as children acquire language unthinkingly with their mothers' milk, so scientists tend to absorb the mechanics of writing research papers unconsciously along with their supervisors' sour grapes. Consequently, the process of recording and transmitting research information is seen by most scientists as straightforward-apart from arguments with editors and referees" (Meadows, 1985). The gap between the 'two cultures' has never been wider: most training strategies still consider the realm of science and the society outside research as two separate worlds, the latter being the 'real' world. The relationship between language and science is overlooked if not ignored totally. Some courses in scientific writing even reinforce conformity to the 'ready-to-write' impersonal hedging model.

$\mathrm{t}$ is young researchers who pay the price: the soft skills_critical thinking, the capacity to devise concepts, the ability to defend one's ideas and to connect to society (GRAD, 2001) —are hard to acquire or develop in the present research 
environment. However, the future of young scientists in an increasingly demanding job market depends on these skills and on their ability to provide evidence of their competency. More than just geographical, mobility must be intellectual and epistemological: by changing levels of analysis to address complexity, by changing scope to move from general to specific questions and objectives to issues, and by being able to communicate with a wider audience. It will require new educational environments and methods to achieve these objectives (Van den Bor et al, 2000).

These arguments against the communication style of scientists can be considered as trespassing on the researchers' 'secret garden' or threatening their sacred autonomy. But as the French philosopher Bruno Latour argues, researchers will gain autonomy only if and when they agree to share their questions with their fellow citizens (Latour \& Porter, 2004). This requires the will to communicate efficiently.

\section{REFERENCES}

AFNOR (1984) Recommandations aux Auteurs des Articles Scientifiques et Techniques pour la Rédaction de Résumés. Norme AFNOR NF Z 44-004. Paris, France: Association Française de Normalisation

AFNOR (2001) Démarche Qualité en RecherchePrincipes Généraux et Recommandations. Norme AFNOR X50-550. Paris, France: Association Française de Normalisation
ANSI (1979a) American National Standard for Writing Abstracts. Washington, DC, USA: American National Standards Institute

ANSI (1979b) American National Standard for the Preparation of Scientific Papers for Written or Oral Presentation. Washington, DC, USA: American National Standards Institute

Day RA (1989) How to Write \& Publish a Scientific Paper. Cambridge, UK: Cambridge University Press

EFB (2004) Who Should Communicate with the Public and How? Barcelona, Spain: European Federation of Biotechnology

ESF (2000) Good Scientific Practice in Research and Scholarship. Strasbourg, France: European Science Foundation

Franzen M, Rödder S, Weingart P (2007) Fraud: causes and culprits as perceived by science and the media. EMBO Rep 8: 3-7

Gascoigne T (2001) Science meets Parliament in Canberra. EOS Trans AGU 82: 515

GRAD (2001) Joint Statement of Skills Training Requirements of Research Postgraduates. Cambridge, UK: GRAD

Hyland K (1998) Hedging in Scientific Research Articles. Amsterdam, The Netherlands: John Benjamins

ICMJE (2006) Uniform Requirements for Manuscripts Submitted to Biomedical Journals: Writing and Editing for Biomedical Publication. Philadelphia, PA, USA: International Committee of Medical Journal Editors

Latour B, Porter C (2004) Politics of Nature: How to Bring the Sciences into Democracy. Boston, MA, USA: Harvard University Press

Lawrence PA, Locke M (1997) A man for our season. Nature 386: $757-758$

Meadows AJ (1985) The scientific paper as an archaeological artefact. / Inf Sci 11: 27-30

Montgomery SL (2003) The Chicago Guide to Communicating Science. Chicago, IL, USA: University of Chicago Press
Pérec G (1980) Experimental demonstration of the tomatotopic organization in the Soprano (Cantatrix sopranica L.). Banana Split 2: 63-74

Roland MC (1995) Analyse des Pratiques Scripturales des Scientifiques. PhD Thesis, Grenoble, France: University of Grenoble III

Roland MC, Chevre AM, Chadoeuf J, Hubert B, Bonnemaire J (2002) Think forward, act now: training young researchers for sustainability. Reshaping the relationship between PhD student and advisor. In Copernicus in Lüneburg: Higher Education in the Context of Sustainable Development and Globalization, $\mathrm{R}$ van Dam-Mieras, G Michelsen, HP Winkelmann (eds). Frankfurt/Main, Germany: VAS

Van den Bor W, Holen P, Wals AE, Leal W (2000) Integrating Concepts of Sustainability into Education for Agriculture and Rural Development. Frankfurt, Germany: Peter Lang

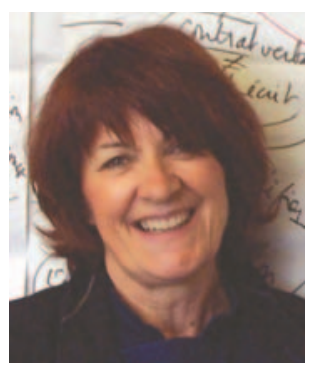

Marie-Claude Roland is Director of Linguistics \& Research Practices at the French National Institute for Agricultural Research in Paris, France. E-mail:roland@paris.inra.fr

doi:10.1038/sj.embor.7400964 